\title{
Hand-telephones face US radiotelescope ban
}

Washington. The US Federal Communications Commission (FCC) has proposed a prohibition on the use of hand-held telephones which communicate via satellites within 100 miles of selected radiotelescopes - including large dishes in Puerto Rico, West Virginia and New Mexico - when certain observations are in progress. The new rules have been drawn up in response to the concerns of radioastronomers about the threat of 'noise pollution' from proposed satellite systems in low Earth orbit.

In addition to restrictions on telephone use near large facilities, the rules would create smaller protected zones around each of the ten antennas that make up the Very Long Baseline Array.

More than half-a-dozen companies, including Motorola, TRW and Loral, have announced plans to launch large constellations of small satellites to act as telephone relays in low orbit. The FCC has allocated two radio bands to these proposed systems: that from 1,610 to $1,626.5 \mathrm{MHz}$ for 'uplink' to the satellites, and that from $2,483.5$ to $2,500 \mathrm{MHz}$ for transmissions down to the ground.

The uplink band includes one of the

spectral lines of the hydroxyl radical, which is of particular interest to astronomers because it holds clues to the nature of interstellar matter and star formation. To reduce radio noise, the National Science Foundation(NSF)'s electromagnetic spectrum management office would notify satellite operators of any planned observations at these wavelengths so that they could switch the uplink temporarily to another frequency or take some other action to avoid interference.

The downlink band is not used heavily for radio astronomy. But the spectral region around its second harmonic - near 5,000 $\mathrm{MHz}$ - is used for continuum observations. The FCC rule would limit the amount of noise satellites produce in this and other protected regions outside their main transmitting frequency.

Tomas Gergely, NSF programme manager for electromagnetic spectrum management, admits that the filters to block these out-of-band signals might cost "a fair amount of money". But he says that satellite owners have shown a willingness to accommodate the needs of astronomers.

John Windolph, a spokesman for the Motorola-led Iridium consortium, says that

\section{CERN seeks firm commitment to LHC}

Munich. The council of the European Laboratory for Particle Physics (CERN) last week reaffirmed its intention of approving the building of its Large Hadron Collider (LHC) at its meeting in June. But the council failed to reach agreement on the precise wording of the resolution on which the members will vote. Some member states are keen that the wording should include a firm commitment to the construction of the LHC, regardless of whether additional funding is promised by non-member states.

Provisional plans are that the $\mathrm{LHC}$ would be built over the ten years 1995-2005. Under current estimates, it will cost 2.6 billion Swiss francs (US\$1.8 billion), which is SFr500 million more than CERN's 19 member states would pay out of their regular contributions during this period.

Christopher Llewellyn-Smith, CERN's director-general, is now trying to raise the shortfall from non-member states, including the United States, Japan and Canada.

If Llewellyn-Smith fails to raise the additional funds, his fall-back is to extend the construction phase by two years (see Nature 366,$714 ; 1993$ ). But he is finding it difficult to persuade non-member countries to commit themselves to the project because it has not yet received approval from CERN members themselves.

Delegates at last week's council meeting approved the substance of a resolution pro- posed by Llewellyn-Smith endorsing this strategy, but said that they needed a few more weeks to fine-tune its wording. In particular, the council members indicated that they want to avoid any ambiguity over the fact that their approval of the LHC will not depend on the promise of outside funding, insisting that such funding should be looked on as a 'bonus' which would make possible an optimal timetable.

The resolution asks for a comprehensive review of the LHC's proposed construction programme in 1997, when the first major outlay for the purchase of magnets is scheduled. By this time the extent of cooperation with non-member states should be clearer.

In particular the US is expected to have reached a firm decision by that date about its own high-energy physics programme, now that it has scrapped plans for the Superconducting Super Collider (SSC). This makes it possible for CERN to construct a definitive timetable for the remaining activities.

- There was celebration among LHC scientists last Thursday when LHC's first 10metre prototype superconducting magnet, developed by CERN and the Italian Institute for Nuclear Physics, exceeded hopes by reaching a field of 8.67 tesla, 0.02 tesla higher than its target. The magnet, one of seven prototypes designed at CERN, reached 8.73 tesla in a second test, maintaining this level for 15 minutes.
Alison Abbott

\section{IMAGE UNAVAILABLE FOR COPYRIGHT REASONS}

Arecibo already suffers 'noise' pollution. "it's the responsibility of those entering the spectrum at a later date to co-ordinate with those who were there first". He believes that all the satellite systems will support the rule being proposed by the FCC.

The new rules are based on the outcome of negotiations that took place last year between representatives of the satellite communications industry and radioastronomers. The National Research Council's Committee on Radio Frequencies (CORF) is to file a letter in support of the rule, and expects no major opposition from the satellite owners. (The proposed rules are open for public comment until 5 May.)

Michael Davis, project scientist for upgrading the Arecibo Observatory in Puerto Rico and chairman of the CORF, describes the negotiations as a good model of the way in which astronomers can work with industry to find mutually satisfactory solutions. "You don't simply throw up your hands in horror and try to fight Wall Street," he said.

Arecibo has a petition before the FCC to establish a 'coordination zone' under which the observatory would automatically be notified whenever anyone in Puerto Rico applied for a broadcast licence. In the past, astronomers at Arecibo have had to deal with radio interference caused by everything from cellular telephones to a nearby religious television station.

US military satellites designed to detect nuclear bursts pose another problem, according to Davis. He estimates that five per cent of the observing time at Arecibo is lost because of signals from these spacecraft. Although satellite operators are meant to notify astronomers before such signals are transmitted, they do not always do so.

One piece of good news for radio observers is that managers of the Russian GLONASS navigation satellites, one of the worst offenders in the area of noise pollution, have agreed to shift its transmission frequencies. The decision was reached last autumn, after years of protest from the scientific community.

Tony Reichhardt 